Egyptian

Orthodontic Journal

\title{
TREATMENT OF DEVELOPING CLASS II DIVISION 1 MALOCCLUSION WITH JUMPER TWIN BLOCK
}

\author{
Eithar S. Bashir*, Shaza M. Hammad**, \\ Ahmed A. El-bialy***
}

\section{ABSTRACT}

Objective: This study was carried out to determine dental and skeletal effects of the Jumper twin 6lock appliance in the treatment of developing Class II, Division I malocclusion. Methods: 15 girls aged 9 to 11 years old with class II division 1 and same physical maturation status were included in the study over one year. Cephalometric data and study models were analyzed statistically with Paired t-test. Results: The Jumper Twin block had skeletal and dental effects. Stimulation of forward mandibular growth, backward displacement of the maxilla, significant increase in the anterior and posterior facial height, retroclination of the upper incisors, proclination of the lower incisors and significant improvement of the overjet and overbite had been found. Conclusions: The Jumper Twin Block appliance with gradual bite advancement was effective in treatment of developing Class II division 1 malocclusion.

\section{INTRODUCTION}

Class II is one of the most common malocclusions especially Class II division 1 which represents about $21 \%$ of Egyptian population ${ }^{(1)}$. About two thirds of typical Class II malocclusion is mostly due to mandibular retrusion ${ }^{(2)}$. A therapy able to enhance mandibular growth is indicated in these patients.

\footnotetext{
* Senior resident, private practise, Dr. Bakhsh Hospital, Jada, Saudi Arabia.

${ }^{* *}$ Lecturer of orthodontics, Faculty of Dentistry, Mansoura University.

${ }^{* * *}$ Professor of orthodontics, Faculty of Dentistry, Mansoura University.
} 
A wide range of functional appliances aiming to stimulate mandibular growth by forward posturing of the mandible is available to correct this type of skeletal and occlusal disharmony; such as the bionator $^{(3)}$, the FR-2 appliance of Fränkel $^{(4,5)}$, the fixed and removable types of Herbst appliances ${ }^{(6,7)}$, the Jasper Jumper ${ }^{(3)}$ and Twin-block $(\mathrm{TB})^{(8)}$ appliance which has gained increasing popularity during the last decade due to its high patient acceptability and its ability to produce rapid treatment changes. The TB was developed by William J. Clark, Scotland, for use in the correction of Class II malocclusions characterized in part by mandibular skeletal retrusion ${ }^{(8)}$.

One of the drawbacks of the original design was the inconvenience of reactivating the appliance to achieve an edge to edge protrusive position in some patients to enable full overjet reduction ${ }^{(9,10)}$.

In a trial to overcome this drawback, this study will be conducted to evaluate the gradual advancement of the bite by adding Bite-Jumping Screw to the original TB in management of Class II division 1.

\section{MATERIAL AND METHODS}

The sample of this study consisted of fifteen female patients. The mean age of the patients was 10 years 6 months. The patients were selected from the Orthodontic Department, Faculty of Dentistry, Mansoura University according to the following criteria: Skeletal class II malocclusion due to mandibular retrusion, All patients were in the mixed dentition, Overjet more than $7 \mathrm{~mm}$, Minimal transverse discrepancy between the maxillary and mandibular arches and no abnormal oral habits. For each patient diagnostic records were made as photographs (intraoral \& extraoral), upper and lower orthodontic casts and radiographs (Lateral Cephalometric, Panoramic and Hand Wrist radiographs).

All records were made before and after treatment except the hand wrist and panoramic x-ray films which were taken only before treatment. Lateral cephalometric radiographs for all subjects were taken with the same machine and the same settings and traced on acetate paper then the following points were recorded: S, Sella; A, Subspinale; ANS, Anterior 
Nasal Spine; N, Nasion; B, Supramentale; PNS, Posterior Nasal Spine; Go, Gonion; Me, Menton; Ar, Articulare; Or, Orbital; P, Porion. The angles measured were SNA, SNB, ANB, Upper incisal angles (UI-NA, UI-SN, UI-PP), Lower incisal angles (LI-MP, LI-NB), Interincisal angle (UI-LI). The linear distances measured were: Ar-A, Ar-B, N-ANS, ANS-Me, Ar-Go, S-Go. Superimposition was done for pre and posttreatment cephalometric radiographs. Overbite, overjet, intercanine and intermolar widths were measured on the cast for every patient.

\section{The appliance construction:}

The initial wax bite was taken with the mandible protracted approximately $5 \mathrm{~mm}$ and opened vertically by about $4 \mathrm{~mm}$. To standardize the appliance activation vertically, the construction bite was taken with an Exactobite stick ${ }^{*}$. (Figure 1)
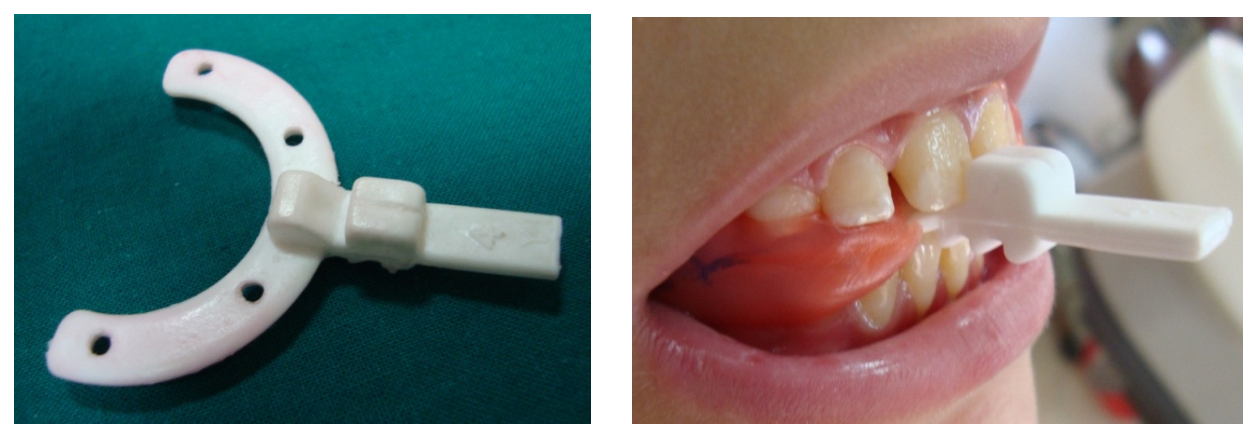

Figure 1: Bite registration with an Exactobite stick.

The basic design of the Twin Block appliance used in this study is illustrated in (Figure 2). This design was similar to the original design by Clark $^{(11)}$ but the maxillary component differs to some extent from the conventional design in that there was bite jumping screw ${ }^{* *}$ (Figure 3) incorporated longitudinally in the upper bite blocks, with the screw head at 70 degree angle to the lower bite blocks.

\footnotetext{
* Forestadent, Milton Keynes, United Kingdom

** ForestadentUSA, 2301 Weldon Parkway, St. Louis, MO 63146
} 
An expansion screw was seated in the midline of the acrylic base plate and activated only if necessary compensatory expansion was needed to accommodate lower arch as the mandible translates forward. The bite jumping screw was opened with a special stainless steel key to be active after eight weeks of twin block wear to give $2 \mathrm{~mm}$ advancement of the bite. Then another $2 \mathrm{~mm}$ was obtained by activation of the screw after another eight weeks. If further correction was needed, there was still $2 \mathrm{~mm}$ of advancement left in the system. An example of a case treated with this appliance is shown in (Figures 4, 5, 6, 7).
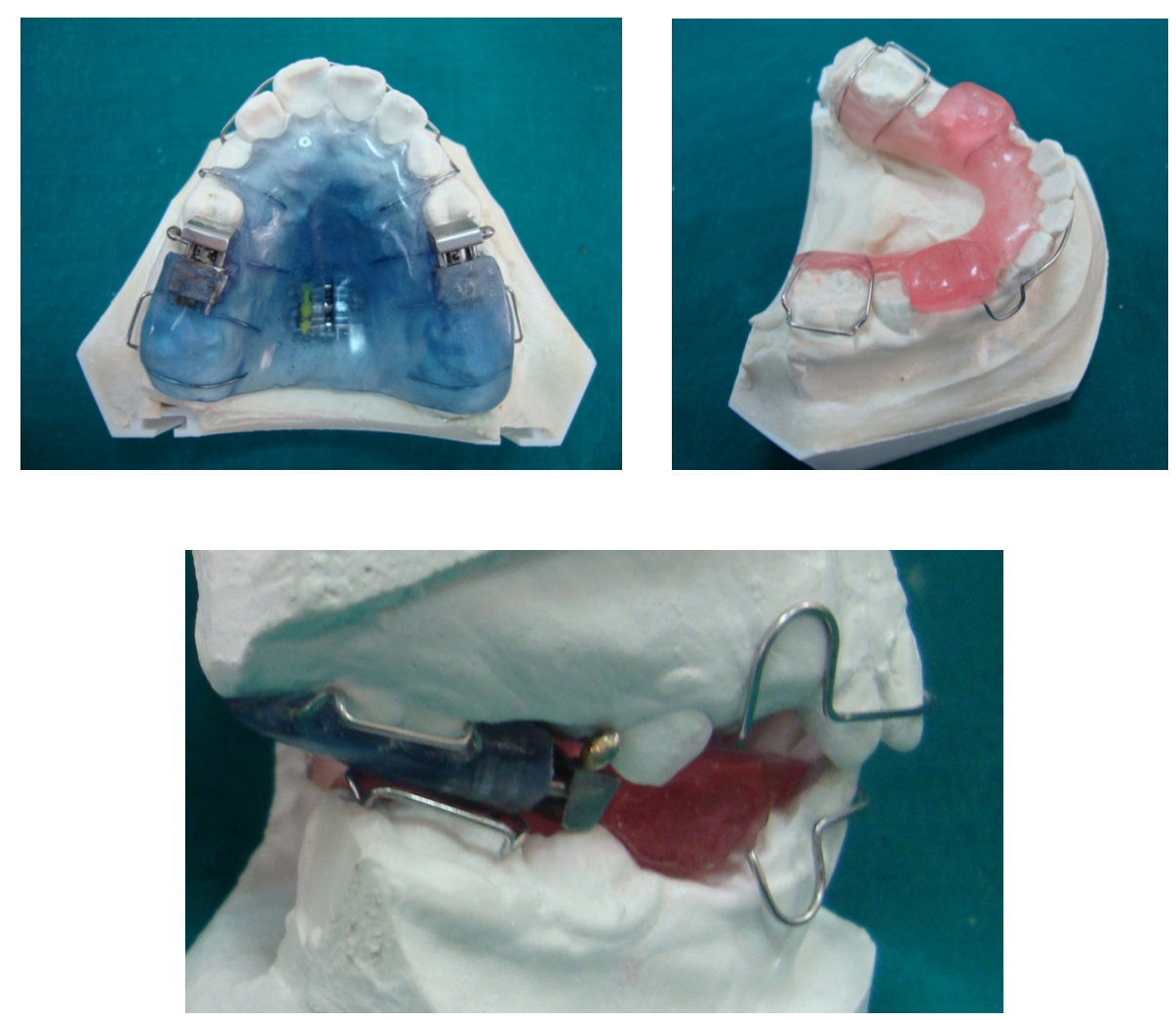

Figure 2: Upper and lower Jumper Twin Block appliance. 
Egyptian

Orthodontic Journal

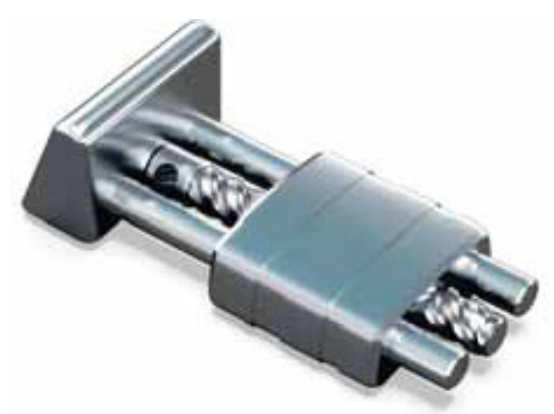

Figure 3: Bite jumping screw.

\section{Statistical analysis:}

All measurements were calculated and analyzed using the SPSS statistical program (Chicago, II). Descriptive statistics including means and standard deviations of the measurements before and after treatment were obtained. Then, Paired $\mathrm{t}$ - test was done to test the significance between the pretreatment and posttreatment measurements. Significance for the statistical test was predetermined at $P<0.05$.

\section{RESULTS}

There was a small but highly statistically significant reduction in SNA angle and Ar-A length which mean growth retardation of the maxilla. On the other hand, mandibular forward growth was stimulated as the SNB angle and Ar-B length were highly significantly increased. The differential growth of the mandible to the maxilla enhanced sagittal relationship; this is evident by highly statistically significant decrease of ANB angle and Wits measurement. The anterior and posterior facial heights (N-Me \& S-Go respectively) were highly significantly increased which mainly due to the down growth of the ramus of the mandible. There was also, significant retroclination of upper incisors and proclination in the lower incisor. This deferential movement in upper and lower incisors lead to a high significant increase in the interincisal angle. Dental cast measurement's revealed a highly significant decrease in the 
overjet and overbite. On the other hand, the intercanine and intermolar widths showed no significant difference except in some cases who needed palatal expansion. (Table I \& II)

Table I: The means, standard deviations (SD) and the results of t-test of the pre and posttreatment cephalometric measurements.

\begin{tabular}{|l|c|c|c|c|}
\hline \multirow{2}{*}{ Measurements } & Pre treatment & Post treatment & t & \multirow{2}{*}{ p-value } \\
\cline { 2 - 4 } & Mean \pm SD & Mean \pm SD & & \\
\hline SNA (Angle) & $81.67 \pm 3.04$ & $80.26 \pm 2.69$ & 10.31 & $0.000^{* *}$ \\
\hline Ar-A (mm) & $86.77 \pm 5.51$ & $85.34 \pm 5.38$ & 11.22 & $0.000^{* *}$ \\
\hline SNB (Angle) & $73.93 \pm 2.34$ & $76.13 \pm 2.72$ & -16.00 & $0.000^{* *}$ \\
\hline Ar-B (mm) & $91.27 \pm 5.42$ & $95.93 \pm 6.96$ & -4.82 & $0.000^{* *}$ \\
\hline ANB (Angle) & $7.66 \pm 1.29$ & $3.86 \pm 0.63$ & 21.56 & $0.000^{* *}$ \\
\hline Wits (mm) & $4.70 \pm 0.70$ & $1.33 \pm 0.36$ & 21.56 & $0.000^{* *}$ \\
\hline N-Me (mm) & $114.66 \pm 7.10$ & $119.06 \pm 6.78$ & -5.98 & $0.000^{* *}$ \\
\hline N-ANS (mm) & $53.00 \pm 5.04$ & $53.73 \pm 5.29$ & -4.78 & $0.000^{* *}$ \\
\hline ANS-Me (mm) & $66.33 \pm 5.36$ & $69.26 \pm 5.27$ & -12.85 & $0.000^{* *}$ \\
\hline Ar-Go (mm) & $39.26 \pm 3.76$ & $40.73 \pm 4.02$ & -11.00 & $0.000^{* *}$ \\
\hline S-Go (mm) & $67.26 \pm 4.89$ & $69.73 \pm 4.86$ & -12.85 & $0.000^{* *}$ \\
\hline UI-NA (Angle) & $27.66 \pm 5.19$ & $18.06 \pm 4.26$ & 19.36 & $0.000^{* *}$ \\
\hline U1-SN (Angle) & $109.26 \pm 5.87$ & $99.73 \pm 7.44$ & 10.60 & $0.000^{* *}$ \\
\hline UI-PP (Angle) & $119.13 \pm 6.17$ & $107.73 \pm 5.47$ & 12.06 & $0.000^{* *}$ \\
\hline LI-MP (Angle) & $95.13 \pm 5.68$ & $97.33 \pm 5.67$ & -12.60 & $0.000^{* *}$ \\
\hline LI-NB (Angle) & $30.13 \pm 5.20$ & $33.33 \pm 5.42$ & -10.81 & $0.000^{* *}$ \\
\hline UI-LI (Angle) & $112.86 \pm 6.22$ & $121.60 \pm 6.03$ & -12.23 & $0.000^{* *}$ \\
\hline
\end{tabular}

** Highly Statistically Significant: $\mathbf{P}<0.001$ 
Table II: The means, standard deviations (SD) and the results of t-test of The pre and posttreatment measurements of dental casts.

\begin{tabular}{|l|c|c|c|c|}
\hline \multirow{2}{*}{ Measurements } & Pretreatment & Posttreatment & \multirow{2}{*}{ T } & \multirow{2}{*}{ p-value } \\
\cline { 2 - 3 } & Mean \pm SD & Mean \pm SD & & \\
\hline Overjet $(\mathrm{mm})$ & $10.03 \pm 1.51$ & $1.60 \pm 0.47$ & 25.52 & $0.000^{* *}$ \\
\hline Overbite \% & $77.66 \pm 11.78$ & $18.00 \pm 4.14$ & 22.91 & $0.000^{* *}$ \\
\hline UICW $(\mathrm{mm})$ & $34.40 \pm 2.26$ & $35.40 \pm 1.18$ & -2.13 & $0.05^{*}$ \\
\hline LICW $(\mathrm{mm})$ & $28.06 \pm 1.79$ & $28.86 \pm 2.23$ & -1.49 & 0.15 \\
\hline UIMW (mm) & $54.53 \pm 1.64$ & $46.20 \pm 1.37$ & -2.19 & $0.04^{*}$ \\
\hline LIMW (mm) & $41.46 \pm 1.64$ & $41.60 \pm 1.76$ & -1.00 & 0.33 \\
\hline
\end{tabular}

** Highly Statistically Significant: $\mathbf{P}<0.001 \quad *$ Statistically Significant: $\mathbf{P}<0.05$ Non Significant: $\mathbf{P}>\mathbf{0 . 0 5}$

UICW = Upper intercanine width. $\quad$ LICW $=$ Lower intercanine width. UIMW $=$ Upper intermolar width.

\section{Case report}

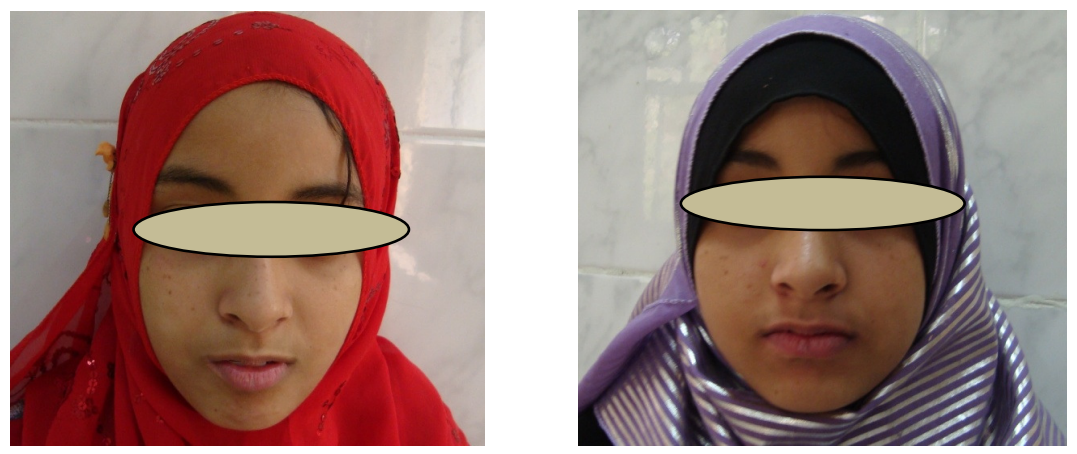

Pre \& Posttreatment frontal view.
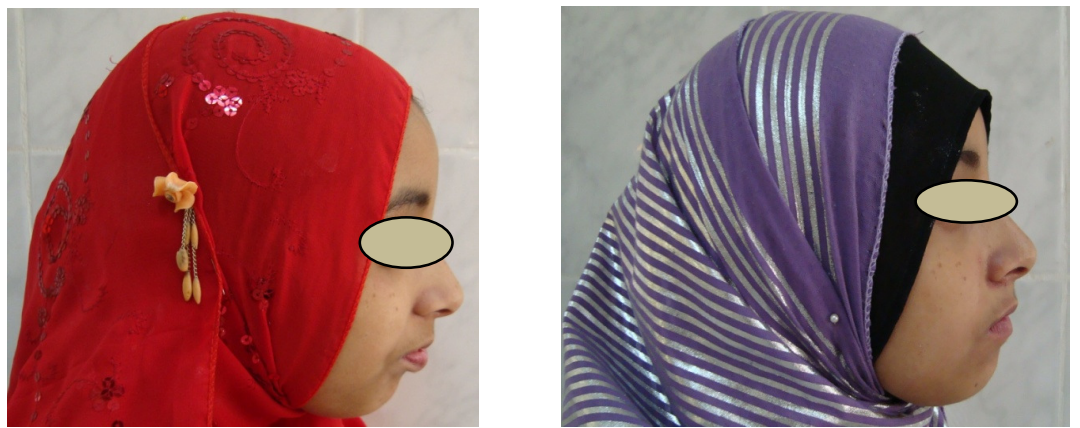

Pre \& Posttreatment lateral view.

Figure 4: Extraoral photographs. 
Egyptian

Orthodontic Journal

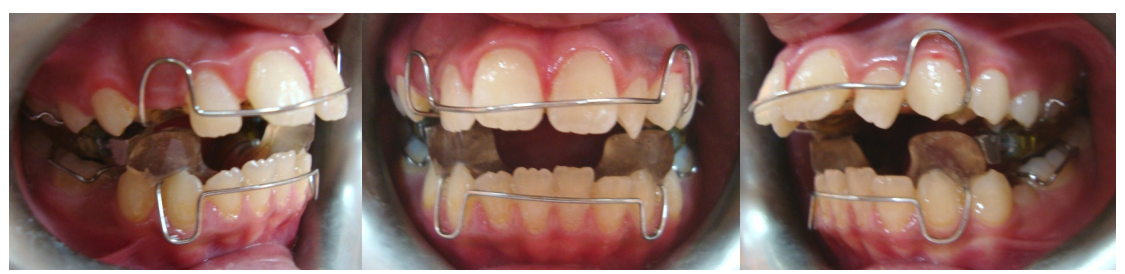

Figure 5: Intraoral photograph with JTB appliance in place.
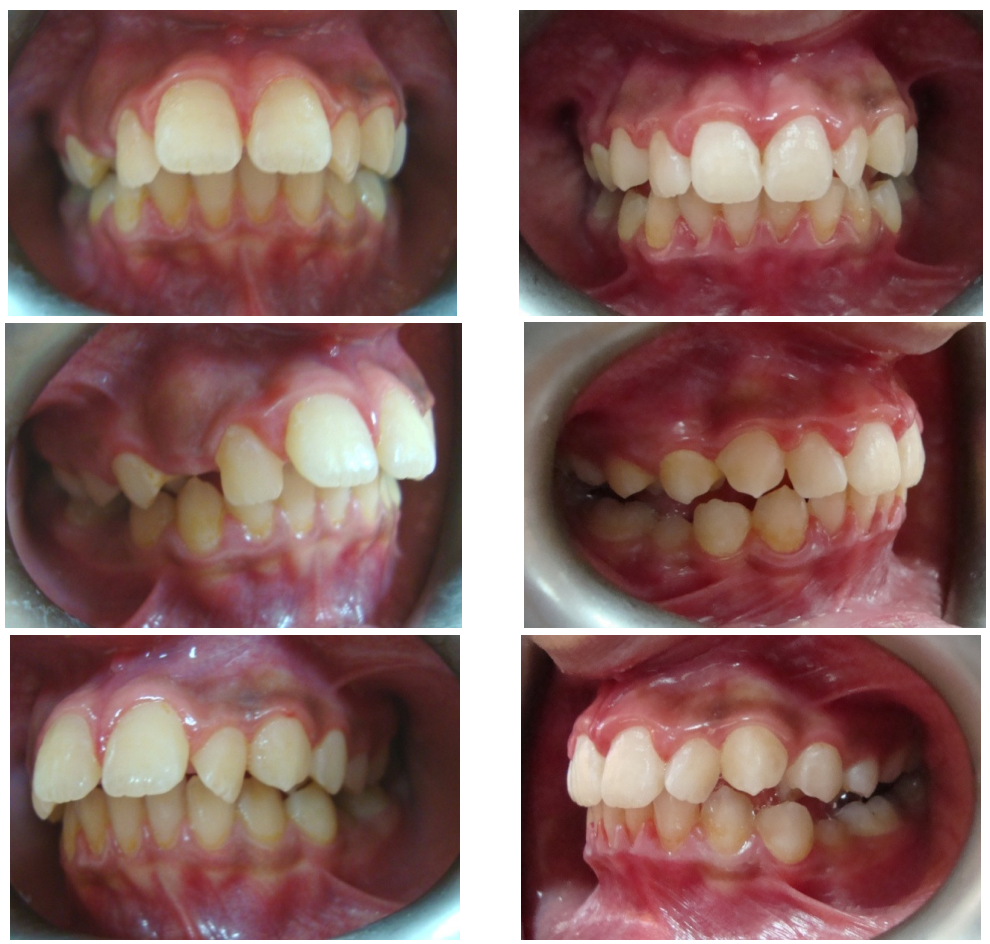

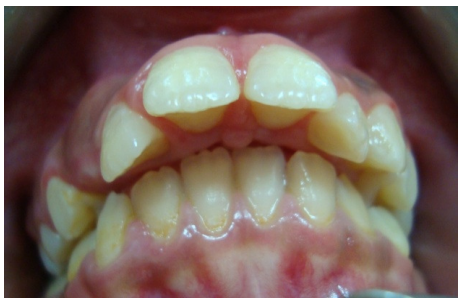

Pretreatment

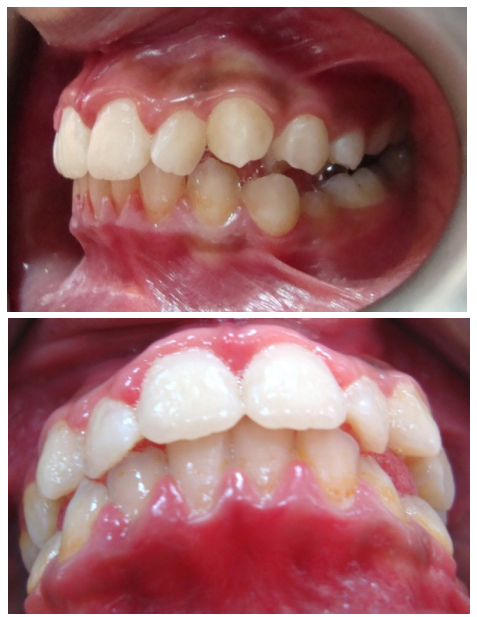

Posttreatment

Figure 6: Intraoral photographs. 
Egyptian

Orthodontic Journal

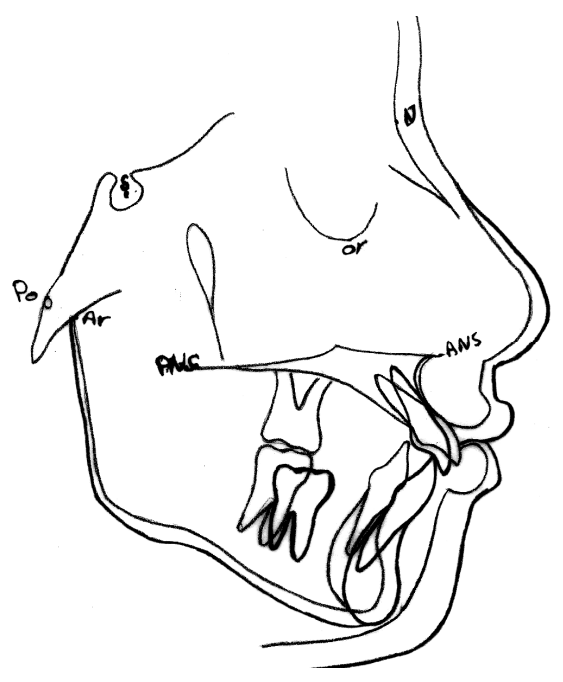

Figure7: Pre and posttreatment cephalometric tracing superimposion.

Black line: Pretreatment tracing.

Red line: Posttreatment tracing.

\section{DISCUSSION}

The Twin-block has gained increasing popularity during the last decade due to its high patient acceptability and its ability to produce rapid treatment changes. ${ }^{(8)}$

One of the drawbacks of the original design was the inconvenience of reactivating the appliance to achieve an edge to edge protrusive position in some patients to enable full overjet reduction. Since many patients are unable to tolerate mandibular protrusion greater than $7 \mathrm{~mm}$, gradual bite advancement is recommended.

Gradual incremental advancement gives a more favourable response to the growth modification process with a reduced effect on incisor tilting. Compliance may be greater with small increments of mandibular advancement by reduction of tension in the craniomandibular musculature. It has been suggested that this improves patient comfort and speech ${ }^{(9,10)}$. This study was one of the pioneer studies to evaluated gradual advancement of the 
Egyptian

Orthodontic Journal

bite by adding Bite-Jumping Screw to the original TB in management of developing Class II Division 1 malocclusion.

In the current study, there was highly significant increase in both the mandibular length (articulare - B point) and SNB angle which indicated stimulation of mandibular growth especially in forward direction. This can be attributed to the adaptive reaction to the forward positioning of the mandible by Jumper Twin Block appliance. This was in agreement with other previous functional appliance studies ${ }^{(12-20)}$. On the other hand, it was in contrast to others ${ }^{(21,22)}$. This dissimilarity in the findings might be explained by the difference in the appliance design.

This study also showed that Jumper Twin Block appliance restrict the forward growth of the maxilla. There were highly significant decrease in both SNA angle and maxillary length (Ar-A Point); this could be due to the change on the dental maxillary base which occurred when the upper incisors were retroclined. These results were similar to previous studies ${ }^{(13,14,17,20)}$. However, opposite results had been observed in others ${ }^{(15,16,23-25)}$. This controversy might be due to the difference in the age of the patients and their growth status during the active phase of treatment.

Consequently, the maxillomandibular relationship improved as manifested by highly significant decrease in the ANB angle and Wits measurement. This outcome was in agreement with other previous studies $^{(15,16,18-20,26)}$. The decrease of ANB angle and Wits analysis were mainly due to the increase in SNB with a small reduction in angle SNA due to backward displacement of the maxilla and forward growth of the mandible by Jumper Twin Block appliance. However, this was in disagreement with the findings of Tümer et al. ${ }^{(27)}$ who evaluated the dentoskeletal effect of Mini-Block appliance and he found that there was no change or a negative change in ANB angle and Wits analysis, which might be due to the fact that his patients were not as compliant as those wearing the TB appliance.

Regarding the vertical dimension, the significant increase in the facial heights could be contributed to larger increase in the height of the mandibular ramus because the appliance design had a greater vertical activation (bite blocks must be at least $4-5 \mathrm{~mm}$ thick vertically). These results were in harmony with many previous studies ${ }^{(12,21,18,19,26,28)}$. But 
were contradicted with others ${ }^{(14,16,17)}$. This controversy could be attributed to the different mode of action between the removable and fixed functional appliances. The most prominent dentoalveolar effect in the treated subjects was retroclination of upper incisors and proclination of lower incisors. Similar findings were reported in other studies ${ }^{(16-19,26,20)}$. This proclination probably was a consequence of the resultant mesial force on the lower incisors induced by the Jumper Twin Block appliance.

These skeletal and dental changes together helped to improve the overjet significantly. This result was in agreement with all other studies pereformed on functional appliances; either fixed or removable ${ }^{(13-20,29)}$. Also, there was significant reduction in the overbite mainly due to increases in the height of the mandibular ramus and the proclination of the lower incisors. This was in agreement with previous studies ${ }^{(13-15,17-19,21)}$. But was not in agreement with the studies of Windmiller ${ }^{(30)}$ and Sidhu et al. ${ }^{(31)}$ because they found that the overbite reduction in their study was mainly due to lower incisors intrusion.

Both the upper and lower intercanine (UICW \& LICW) and intermolar (UIMW \& LIMW) arch widths showed no significant difference except in five patients who needed palatal expansion during their treatment with Jumper Twin Block appliance; significant increase in upper intercanine and intermolar widths was found.

Furthermore, clinical advantages of Jumper Twin block appliance were found: the advancement was measured more accurately; quickly adjustment of the appliance, minimal laboratory support, symmetric gradual advancement and reversible if over advancement was produced.

\section{CONCLUSION}

Early intervention with Jumper Twin Block appliance successfully reduced dental overjet, overbite, molar discrepancies, and severity of malocclusion. This was achieved by a combination of skeletal and dental changes due to growth modification of both the mandible and the maxilla.

The gradual advancement of the bite with Jumper Twin Block improved patient comfort, speech and cooperation. 
Egyptian

Orthodontic Journal

\section{REFERENCES}

1. Fouda MA: Disturbance of the accepted occlusion by extraction. AL-Azhar D J 1987;2(5):453-67.

2. Abd El-Magid MT: Treatment of Developing Class II division I malocclusion with Jasper Jumper. Master thesis, Mansoura University, 1995.

3. Jasper JJ, McNamara JA: The correction of interarch malocclusions using a fixed force module. Am J Orthod Dentofacial Orthop 1995; 108:641-50.

4. McNamara JA, Bookstein FL, Shaughnessy TG: Skeletal and dental changes following functional regulator therapy on Class II patients. Am J Orthod 1985;88:91-110.

5. Fränkel R: The theoretical concept underlying the treatment with functional correctors. Trans Eur Orthod Soc 1966;42:233-54.

6. Pancherz H: Treatment of Class II malocclusions by jumping the bite with the Herbst appliance: a cephalometric investigation. Am J Orthod 1979;76:423-42.

7. Lai M, McNamara JA: An evaluation of two-phase treatment with the Herbst appliance and preadjusted edgewise therapy. Semin Orthod 1998;4:46-58.

8. Clark WJ: The Twin-block technique. In: Graber TM, Rakosi T, Petrovic AG, editors. Dentofacial orthopedics with functional appliances, 2nd edition. St Louis: Mosby-Yearbook, Inc, 1997;268-98.

9. Geserick M, Olsburgh S and Petermann D: The Bite-Jumping Screw for Modified Twin-Block Treatment. JCO 2006;432:435.

10. Carmichael G and Chadwick S: A modification to enable controlled progressive advancement of the Twin Block appliance. Brit $\mathrm{J}$ of Orthod 1999;26:9-13.

11. Clark WJ: The twin block technique: a functional orthopedic appliance system. Am J Orthod 1988;93:1-18.

12. Baccetti T, Faltin K, Franchi L, Ghiozzi B and McNamara J: Long-term Effectiveness and Treatment Timing for Bionator therapy. Angle Orthod 2003;73:221-230. 
13. Bantleon H and Weiland F: Treatment of Class II malocclusions with the Jasper Jumper appliance. Am J Orthod Dentofacial Orthop 1995; 108:341-50.

14. Goyenc Y, Sari Z, Doruk C and Usumez S: Comparative Evaluation of a New Removable Jasper Jumper Functional Appliance vs an Activator-Headgear Combination. Angle Orthod 2003;73:286-293.

15. Freeman D, McNamara J, Baccetti T, Franchi L, Fra“ nkeld C, Arbor A and Zwickau: Long-term treatment effects of the FR-2 appliance of Fra"nkel. Am J Orthod Dentofacial Orthop 2009;135:570.e1-570.

16. Almeidaa M, Henriquesb J, Almeidac R and Mcnamara J: ShortTerm Treatment Effects Produced by the Herbst Appliance in the Mixed Dentition. Angle Orthod 2005;75:540-547.

17. VanLaecken R, Martin C, Dischinger T, Razmus T and Ngane P: Treatment effects of the edgewise Herbst appliance: A cephalometric and tomographic investigation. Am J Orthod Dentofacial Orthop 2006; 130:582-93.

18. Lund D and Sandler P: The effects of Twin Blocks: A prospective controlled study. Am J Orthod Dentofacial Orthop 1998;113:104-10.

19. Mills $\mathrm{C}$ and McCulloch $\mathrm{K}$ : Treatment effects of the twin block appliance: A cephalometric study. Am J Orthod Dentofacial Orthop 1998;114:15-24.

20. Trenouth M: Cephalometric evaluation of the Twin-block appliance in the treatment of Class II Division 1 malocclusion with matched normative growth data. Am J Orthod Dentofacial Orthop 2000;117:54-9.

21. Christopher J, Starke J, Conradt C, Stellzig A and Komposch G: Effects of Early Activator Treatment in Patients with Class II Malocclusion. Angle Orthod 2001;71:120-126.

22. Janson G, Caffer DC, Henriques JF and Neves LS: Stability of Class II, Division 1 Treatment with the Headgear-Activator Combination Followed by the Edgewise Appliance. Angle Orthod 2004;74:594-604.

23. Souza E, Janson G, Freitas M, Henriques F and Cavalcanti C: Occlusal Changes of Class II Malocclusion Treatment between Fränkel and the Eruption Guidance Appliances. Angle Orthod 2004;74:521-525. 
24. Jena A, Duggal R and Parkashc H: Skeletal and dentoalveolar effects of Twinblock and bionator appliances in the treatment of Class II malocclusion: A comparative study. Am J Orthod Dentofacial Orthop 2006; 130:594-602.

25. Jenaa AK: Treatment Effects of Twin-Block and Mandibular Protraction Appliance-IV in the Correction of Class II Malocclusion. Angle Orthod 2010;80:485-491.

26. Toth $\mathrm{L}$ and Mcnamara J: Treatment effects produced by the Twin-block appliance and the FR-2 appliance of Fränkel compared with an untreated Class II sample. Am J Orthod Dentofacial Orthop 1999;116:597-609.

27. Tümer N and Gültan A: Comparison of the effects of monoblock and twin-block appliances on the skeletal and dentoalveolar structures. Am J Orthod Dentofacial Orthop 1999;116:460-8.

28. Nahm D, Ahn S and Kim J: Cephalometric markers to consider in the treatment of Class II Division 1 malocclusion with the bionator. Am J Orthod Dentofacial Orthop 2001;119:578-86.

29. Mills $\mathrm{C}$ and McCulloch $\mathrm{K}$ : Posttreatment changes after successful correction of Class II malocclusions with the Twin Block appliance. Am J Orthod Dentofacial Orthop 2000;118:24-33.

30. Windmiller E: The acrylic-splint Herbest appliance. A cephalometric evaluation. Am J Orthod 1993;104:73-84.

31. Sidhu M, Kharbanda $P$ and Sidhu P: Cephalometric analysis of changes produced by a modified Herbest appliance in the treatment of Class II division 1 malocclusion. Brit J Orthod 1995;22:123-34. 